\title{
'Isolated Rapunzel Tail’ Presenting as Acute Appendicitis
}

\author{
T. Renu Kumar • G. Chinna Rao
}

Received: 3 December 2013 / Accepted: 4 March 2014 / Published online: 29 March 2014

(C) Dr. K C Chaudhuri Foundation 2014

To the Editor: An 11-y-old girl, presented with pain abdomen, vomiting and fever for $2 \mathrm{~d}$ with no significant past history. Pallor, toxemia and Mcburney's tenderness were remarkable. Hemoglobin was $7 \mathrm{~g} \%$. Abdominal radiograph showed small bowel obstruction. Abdominal Ultrasonogram showed an inflamed appendix. At surgery, grossly inflamed appendix filled with 'tuft of hair' that surprisingly continued as a 'long chain' of interconnected 'hair balls' into the entire small bowel was found. The 'Rapunzel tail', measuring $1 \mathrm{~m}$ was retrieved by enterotomies and appendectomy. Child developed a reversible endotoxic shock during enterotomy. Postoperative gastroscopy showed no hair. Retrospectively the parents revealed, the child 'secretly ate' hair picked up from the surroundings but gave this up 4 years ago for 'peer teasing'. However, she never had trichotillomania. Postoperative febrile spikes responded to intravenous Flucanazole. Psychiatric evaluation was normal.

In trichophagia, hair trapped in the gastric rugae creates a stomach shaped trichobezoar, the 'Rapunzel head', connected to an 'intestinal tail' of bezoars leading to symptomatic constellation known as 'Rapunzel syndrome'. Isolated small intestinal trichobezoars without a gastric head are extremely rare [1], and this 'Rapunzel tail' presenting as acute appendicitis has not been reported hitherto.

Once trichophagia is stopped for some years, the gastric bezoars are propulsed into the intestines by fragmentation or in-toto movement leads to an 'isolated Rapunzel tail' that

T. Renu Kumar $(\bowtie)$

Department of Pediatric Surgery, Vaatsalya Hospital, Three Lamps

Junction, Vizianagaram, Andhra Pradesh 535002, India

e-mail: drtrk2007@rediffmail.com

G. Chinna Rao

Department of Pediatrics, Vaatsalya Hospital, Three Lamps Junction,

Vizianagaram, Andhra Pradesh, India results in small bowel obstruction [2] or rarely appendicitis like in this case.

Trichobezoars causing acute appendicitis is extremely rare and need not be associated with psychosomatic disorder or trichophagia [3]. Appendix being the most dependent hollow viscus; hair strands like other foreign bodies can lodge in its lumen and cause appendicitis [4]. Hair in the appendix mandates small bowel examination; conversely, appendix should be examined for hair in Rapunzel syndrome [5].

Ultrasonogram and abdominal radiograph can miss intestinal trichobezoars due to its rarity and lack of suspicion [1]. Trichobezoars are 'highly toxic' and offensive due to the prolonged microbial overgrowth in the decomposed food residue trapped in them. Spillage during enterotomy may precipitate endotoxic shock and toxemia. Higher antibiotics and additional antifungals may also be required to counter the possible fungal overgrowth in trichobezoars. Majority of them present with complications hence all trichobezoars should be addressed early.

\section{Conflict of Interest None.}

Role of Funding Source None.

\section{References}

1. Nair MS, Nair BM. A rare presentation of Rapunzel syndrome manifesting in the immediate post-appendicectomy period. Int J Surg. 2008; 14:2. doi:10.5580/1dee.

2. Zamir N, Akhtar J, Ahmed S. Delayed presentation of trichobezoar with small bowel obstruction. APSP J Case Rep. 2011;2:6.

3. Dehghan A, Moaddab AH, Mozafarpour S. An unusual localization of trichobezoar in the appendix. Turk J Gastroenterol. 2011;22:357-8.

4. Renu Kumar T, Bawa M, Ragavan M. The metallic screw appendicitis. Indian J Pediatr. 2010;77:337.

5. Dogra S, Yadav YK, Sharma U, Gupta K. Rapunzel syndrome causing appendicitis in an 8-year-old girl. Int J Trichol. 2012;4:278-9. 